\title{
An Infraspec VFA-IR spectrometer analysis of Trans-fat content in glazed donuts purchased from supermarkets, convenience stores and bakeries
}

\author{
Sharron Jenkins* and Patty Campbell
}

Georgia Gwinnett College, 1000 University Lane, Lawernceville Ga, USA and Purdue University North Central, 1401 S US HWY 421 Westville Indiana

\begin{tabular}{l}
\hline C H R O N I C L E \\
\hline Article history: \\
Received October 21, 2014 \\
Received in revised form \\
January 29, 2015 \\
Accepted 9 March 2015 \\
Available online \\
10 March 2015 \\
\hline Keywords: \\
Trans-fat \\
Baked goods \\
Donuts \\
Spectroscopy \\
ATR-FTIR
\end{tabular}

\begin{abstract}
A B S T R A C T
Most packaged food products must contain trans-fat labelling; however unpackaged snacks such as cookies, donuts, and muffins at supermarkets, gas station convenience stores, and bakeries often do not have or require nutrition fact labels. Hence, consumers are not aware of the trans-fat content in unpackaged food products. It is well-known within the health and scientific community that diets high in trans-fat can lead to a host of health problems, namely coronary heart disease (CHD). The purpose of this study is to conduct a preliminary study of the trans-fat content in unpackaged baked goods, particularly unpackaged glazed donuts. To accomplish our objective, we determined the \% trans-fat in oil extracted from glazed donuts obtained from several supermarkets, gas stations and bakeries across Northwest, Indiana. Variable Filter Array (VFA) IR spectroscopy was used to assess the trans-fat content of oil extracted from food samples. In this paper, we present our preliminary findings.
\end{abstract}

(C) 2015 Growing Science Ltd. All rights reserved.

\section{Introduction}

A trans-fat (Fig. 1) is a fat molecule containing one or more unsaturated fatty acids in the trans configuration. Although trace amounts may be found in milk and meat products, unhealthy levels of trans-fats are generated industrially in fats and oils during a process called hydrogenation. Hydrogenation is a process that transforms unsaturated liquid vegetable oil into a partially hydrogenated semisolid fat that has an increased oxidative stability and shelf life ${ }^{1}$. Studies have shown that diets that are high in industrially generated trans-fats raise "bad cholesterol" also known as lowdensity lipoprotein (LDL), decrease high-density lipoprotein (HDL) and increase the risk of strokes and coronary heart disease (CHD). Sudden death, adiposity, type 2 diabetes, obesity, and other chronic illnesses have also been linked to trans-fat consumption ${ }^{2-4}$. Americans intake an average of 5.8 grams of trans-fat a day and according to the American Heart Association, and an intake of just 5 grams of trans-fat a day is linked to a 25 percent increase in the risk of ischemic heart disease ${ }^{5-7}$. Hence, the

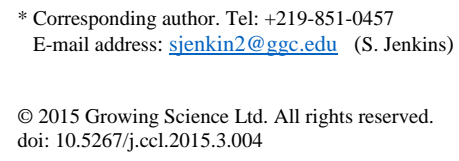


American Heart Association recommends limiting the amount of dietary trans-fat consumption to less than 2 grams a day ${ }^{8}$.

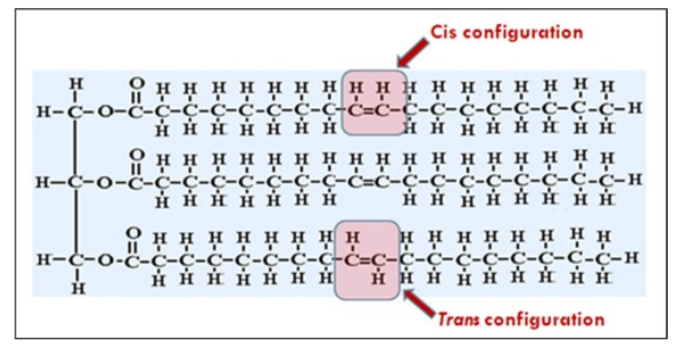

Fig. 1. A formula of fat (cis/trans configurations)

In 2003 the U.S. Food and Drug Administration (Food and Drug Administration 2003) required that "...trans fatty acids be declared in the nutrition label of conventional foods and dietary supplements" to help consumers make healthy dietary choices ${ }^{5}$. In November of 2013, the FDA published the following notice: “...partially hydrogenated oils (PHOs), which are the primary dietary source of industrially-produced trans fatty acids, or trans-fat, are not generally recognized as safe..."9. Although U.S. health officials are very close to completely eliminating trans-fat from the American diet; presently there are no federal regulations of trans-fat labelling for unpackaged food products ${ }^{2-4}$. New York City, Boston (Massachusetts), Chicago (Illinois), Albany County of New York, King County of Washington, Colorado, Philadelphia, and California have all adopted some form of legislation that regulate, limits, or bans the use of industrially produced trans-fats ${ }^{10-13}$. In some cases, the regulations do not apply to baked goods, such as donuts.

In a previous study, our lab developed a method for rapid VFA-IR spectroscopic analysis of transfat in neat oil samples extracted from fast food French fries ${ }^{14}$. The purpose of this study is to conduct a preliminary analysis of trans-fat content in unpackaged baked goods, particularly unpackaged glazed donuts. The donuts were purchased from supermarkets, gas stations, and bakeries in northwest Indiana. When possible, we compared our findings with the percent trans-fat found in restaurant literature (nutrition fact table).

Rapid VFA-IR spectroscopy is used to determine the total isolated trans-fatty acids in oil samples extracted from LJS's food items ${ }^{14-19}$. This type of IR analysis is based on a C-H "out-of-plane" deformation that is characteristic of all compounds containing an isolated trans double bond configuration. The trans configuration results in a unique IR absorbance band at $966 \mathrm{~cm}^{-1}$ and the intensity of this absorption band can be used to determine trans-fat content in a variety of fat samples ${ }^{16}$.

\section{Results and Discussion}

We have chosen not to associate the data in our study with the corresponding establishments; therefore all establishments in our results (data tables, graphs, and charts), discussion and conclusion will be identified by the numbers 1 through 15. Table 1 and Fig. 2 show the experimental mean (and standard deviation from mean) of three trials (two trials for Establishments 3 and 8) of the \%trans-fat and \%fat in oil extracted from glazed donuts. The mean values for donut oil purchased from Establishments 3 and 8 were the averages of Trials 2 and 3. In Trial 1 (April), oil extractions from donuts purchased from Establishment 3 contained 41.0\% trans-fat and by Trial 2 and 3 (June and July) no trans-fat was detected. The oil extraction from donuts purchased from Establishment 8 on the other hand, went from $4.0 \%$ in Trial 1 to over $30.0 \%$ by Trial 2 . The drastic differences seen in Trial 1 compared to Trials 2 and 3 may be due to a difference in method of preparation, specifically the type of oil or fat used. 
Three out of the 15 locations studied had donut nutrition fact tables (trans-fat information) available for consumer viewing: Establishment 5 (26.7\%), Establishment 14 (0.0\%) and Establishment 15 (0.0\%). Establishment 5 reported 26.67\% compared to our findings of $30.7 \% \pm 3.2$; and Establishments 14 and 15 reported $0.0 \%$, which is in agreement with our findings. All other locations, Establishments $1-8,10,11$ and 13 had no information available for comparison. The average percent of trans-fat found in donut oil extracts were over 30\% for the following locations of donut purchase: Establishment 10 (40.5 \pm 4.5), Establishment 9 (39.1 \pm 5.3), Establishment 6 (36.5 \pm 2.2), Establishment 12 (36.5 \pm 2.4$)$, Establishment 13 (35.2 \pm 1.0$)$, Establishment 5 (30.7 \pm 3.2$)$, and Establishment 8 (37.6 \pm 4.8). Statistically, Establishments 1, 2, 4, 7, 11, 14, and 15 had no significant or no detectable levels of trans-fat (Table 1).

The total percent fat in each donut sample was also obtained; however there were no restaurant literature available for comparison. Donuts purchased from Establishments 1 - 4, 7, 11, 14 and 15 contained less than $4.0 \%$ fat. Donuts purchased from all other location had a fat content between 30.0 and $40.0 \%$.

Table 1. A comparison of the experimental and literature values for \%trans-fat and \%fat in oil extracted from glazed donuts purchased from select establishments across Northwest Indiana. For all locations, except Establishments 3 and 8, the mean value of three trials is shown. *The mean value for Establishments 3 and 8 were the averages of Trials 2 and 3

\begin{tabular}{|c|c|c|c|c|c|}
\hline \multirow[b]{2}{*}{ Establishments } & \multicolumn{3}{|c|}{ \%Trans-fat in Glazed Donuts } & \multirow{2}{*}{$\begin{array}{c}\text { \%Trans-fat } \\
\text { Experimental } \\
\text { Mean }(\mathbf{n}=3)\end{array}$} & \multirow{2}{*}{$\begin{array}{c}\text { \%Fat } \\
\text { Experimental } \\
\text { Mean }(\mathbf{n}=3) \\
\end{array}$} \\
\hline & $\begin{array}{l}\text { Trial } 1 \\
\text { (April) }\end{array}$ & $\begin{array}{c}\text { Trial } 2 \\
\text { (June) }\end{array}$ & $\begin{array}{c}\text { Trial } 3 \\
\text { (July) }\end{array}$ & & \\
\hline Establishment 1 & 1.0 & 0.0 & 1.34 & $0.8 \pm 0.7$ & $14.1 \pm 2.7$ \\
\hline Establishment 2 & 3.0 & 0.6 & 0.35 & $1.3 \pm 1.5$ & $12.2 \pm 0.6$ \\
\hline Establishment $3^{*}$ & 41.0 & 0.8 & 0.0 & $0.4 \pm 0.5$ & $12.3 \pm 1.2$ \\
\hline Establishment 4 & 0.0 & 0.7 & 0.83 & $0.5 \pm 0.5$ & $15.0 \pm 1.1$ \\
\hline Establishment 5 & 29.0 & 34.4 & 28.8 & $30.7 \pm 3.2$ & $14.7 \pm 4.5$ \\
\hline Establishment 6 & 34.0 & 38.0 & 37.6 & $36.5 \pm 2.2$ & $16.9 \pm 1.7$ \\
\hline Establishment 7 & 3.0 & 0.00 & 0.0 & $1.0 \pm 1.7$ & $18.9 \pm 3.5$ \\
\hline Establishment 8* & 4.0 & 34.26 & 41.0 & $37.6 \pm 4.8$ & $16.9 \pm 9.8$ \\
\hline Establishment 9 & 33.0 & 41.2 & 43.0 & $39.1 \pm 5.3$ & $12.3 \pm 1.6$ \\
\hline Establishment 10 & 35.0 & 42.6 & 43.8 & $40.5 \pm 4.5$ & $14.6 \pm 2.5$ \\
\hline Establishment 11 & 3.0 & 1.6 & 0.8 & $1.8 \pm 2.4$ & $17.1 \pm 0.5$ \\
\hline Establishment 12 & 39.0 & 34.3 & 36.2 & $36.5 \pm 2.4$ & $15.5 \pm 1.2$ \\
\hline Establishment 13 & 35.2 & 36.0 & 32.8 & $35.2 \pm 1.0$ & $15.4 \pm 1.6$ \\
\hline Establishment 14 & 7.0 & 0.2 & 1.31 & $2.8 \pm 3.6$ & $23.4 \pm 1.7$ \\
\hline Establishment 15 & 5.0 & 4.0 & 2.6 & $3.9 \pm 0.0$ & $13.6 \pm 0.8$ \\
\hline
\end{tabular}

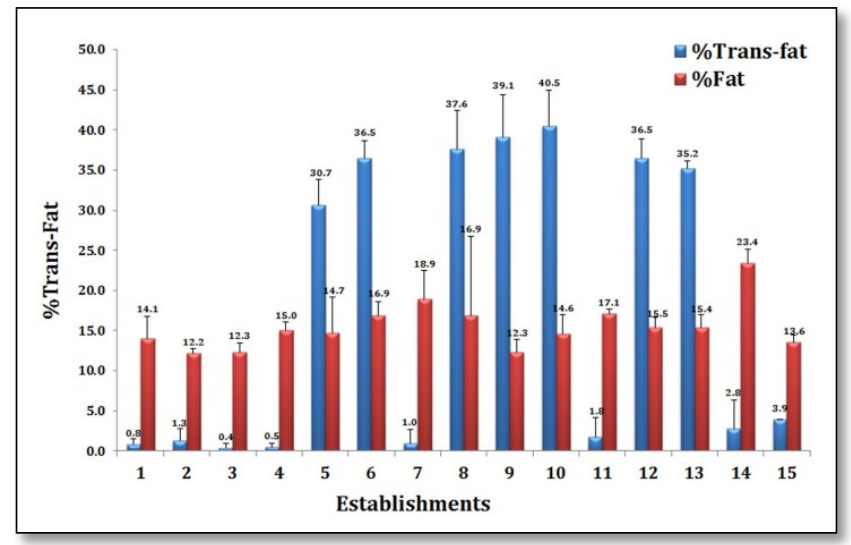

Fig. 2. \%Trans-fat and \%fat values for donuts purchased from supermarkets, convenience stores, and bakeries in Northwest Indiana. Each establishment is identified by the numbers $1-15$ in order to disassociate the data from the corresponding establishment 


\section{Conclusions}

Based on the results of our study, there is a considerable amount of trans-fat in unpackaged glazed donuts purchased from bakeries, convenience stores and supermarkets across Northwest Indiana. In most cases, the nutrition fact tables were not even available for consumer review. There are no U.S. federal regulations governing the labeling of unpackaged baked goods; hence establishments are not obligated to provide the trans-fat content in their baked goods. We propose that there is a need for federal regulation of trans-fat labelling of unpackaged baked foods so that consumers are able to make healthy and informed choices regarding the purchase of unpackaged food products. Lastly, it should be noted that the results presented in this preliminary study should be approached with some caution since a recent study found that other constituents in edible oils can interfere with the absorption band at 966 $\mathrm{cm}^{-1}$, specifically at trans-fat levels below $2 \%$ of total fat ${ }^{21}$. Future studies are needed to confirm that our adopted methodology gives reliable results.

\section{Acknowledgements}

This research was funded by LSAMP (Louis Stokes Alliance for Minority Participation) and Purdue University North Central.

\section{Experimental}

4.1. Materials and Methods. A detailed method for fat extraction and trans-fat analysis is described in a previous paper ${ }^{14}$; however a brief description is given here.

4.2. Fat Extractions. Donuts were purchased from 15 different grocery, bakery, and/or convenience store locations within cities of Northwest Indiana (Michigan City, South Bend, Valparaiso, and Westville). Glazed donuts were purchased at approximately the same time of day from the following locations: Al's Supermarket (Michigan City), BP gas station (Westville), Casey's (Westville), Chuck's Bakery (Valparaiso), Dunkin Donuts (Michigan City), Family Express (Michigan City), Gas City (Michigan City),

Jewel (Michigan City), Kroger (South Bend), Martin’s Supermarket (South Bend), Meijer (Michigan City), Speedway (Michigan City), Town \& Country (Valparaiso), Walmart (Michigan City), and Wiseway (Valparaiso).

For all locations, three trials were done over a period of three months in 2010. Trial 1 was done in April, Trial 2 in June, and Trial 3 in July. Fat extractions and trans-fat analysis were performed within 24 hours of each purchase. The total fat content was determined using an extraction method described by Jenkins, et al. ${ }^{14}$. For each experiment, one whole donut was homogenized in ligroine (petroleum ether) using a stainless steel blender. The solvent was decanted into a large evaporating dish and the extraction was repeated three times in order to maximize fat extraction. The oil extracts were pooled into one large evaporating dish and the solvent was evaporated over low heat $\left(60^{\circ} \mathrm{C}\right)^{14-19}$ on a hot plate. Solvent evaporation over low heat had little to no effect on our trans-fat data and results ${ }^{14}$. All oil extracts were stored in dark containers at $-20^{\circ} \mathrm{C}$ until IR analysis. See previous study for detail methodology ${ }^{14-16}$.

4.3 VFA-IR Trans-fat Analysis. Trielaidin (trans-fat standard) and triolein (cis-fat standard) were purchased from Nu-Check-Prep, Elysian, MN. Triolein is an oleic acid triglyceride containing only cis double bonds, and trielaidin is an elaidic acid triglyceride containing only trans double bonds. Eight trans-fat calibration standards were prepared by mixing trielaiden and triolein to give percentages of trans-fat between one and $50 \%$ by mass. The standards were used to calibrate the Wilk's InfraSpec Variable Filter Array (VFA) IR spectrometer, which was used to determine the total isolated trans fatty 
acid in all neat oil extracts ${ }^{14,17}$. VFA-IR trans-fat analysis can only be applied to oils and fats with trans-fat levels equal to or greater than about $1.0 \%$.

Previous papers have described methods of rapid trans-fat analysis using various IR spectroscopic techniques ${ }^{14,17-20}$. Unlike most FTIR spectrometers, the Wilk's InfraSpec VFA-IR represents a new concept in mid-IR instrumentation. The instrument has no moving parts, an insignificant optical air path, weighs about $0.450 \mathrm{~kg}$ and is a portable instrument that can be used in the field for onsite \%transfat analysis. The Wilk's InfraSpec VFA-IR is equipped with custom software that allows for multiple calibrations and data storage. Prior to trans-fat analysis of oil extracts, calibration tables were created and stored in the InfraSpec VFA-IR software; then using approximately $100 \mathrm{ul}$ of a neat oil sample, trans-fat content was determined in less than one minute ${ }^{17}$.

The trans-fat absorption bands of standards and samples occurred at $956 \mathrm{~cm}^{-1}$ instead of $966 \mathrm{~cm}^{-1}$ which was within the was $25 \mathrm{~cm}^{-1}$ resolution of the InfraSpec VFA-IR instrument. The area under the 956 $\mathrm{cm}^{-1}$ absorbance band was integrated between the limits of 990 and $945 \mathrm{~cm}^{-1}$ (Figure 3). Triolein (cis fatty acid standard) was used as the background spectrum for all VFA-IR ${ }^{18-20}$. Figure 3 shows the VFAIR absorbance spectra of the eight trans-fat standards and oil samples extracted from the donuts. The calibration of curve of the percent trans-fat versus peak area $\left(945-990 \mathrm{~cm}^{-1}\right)$ of the standards yielded a linear equation of $\mathrm{y}=4.77 \times 10^{-5} \mathrm{x}+1.23 \times 10^{-4}, \mathrm{R}^{2}=0.9904^{14}$. This calibration was stored in the instrument as the calibration for all trans-fat analyses.

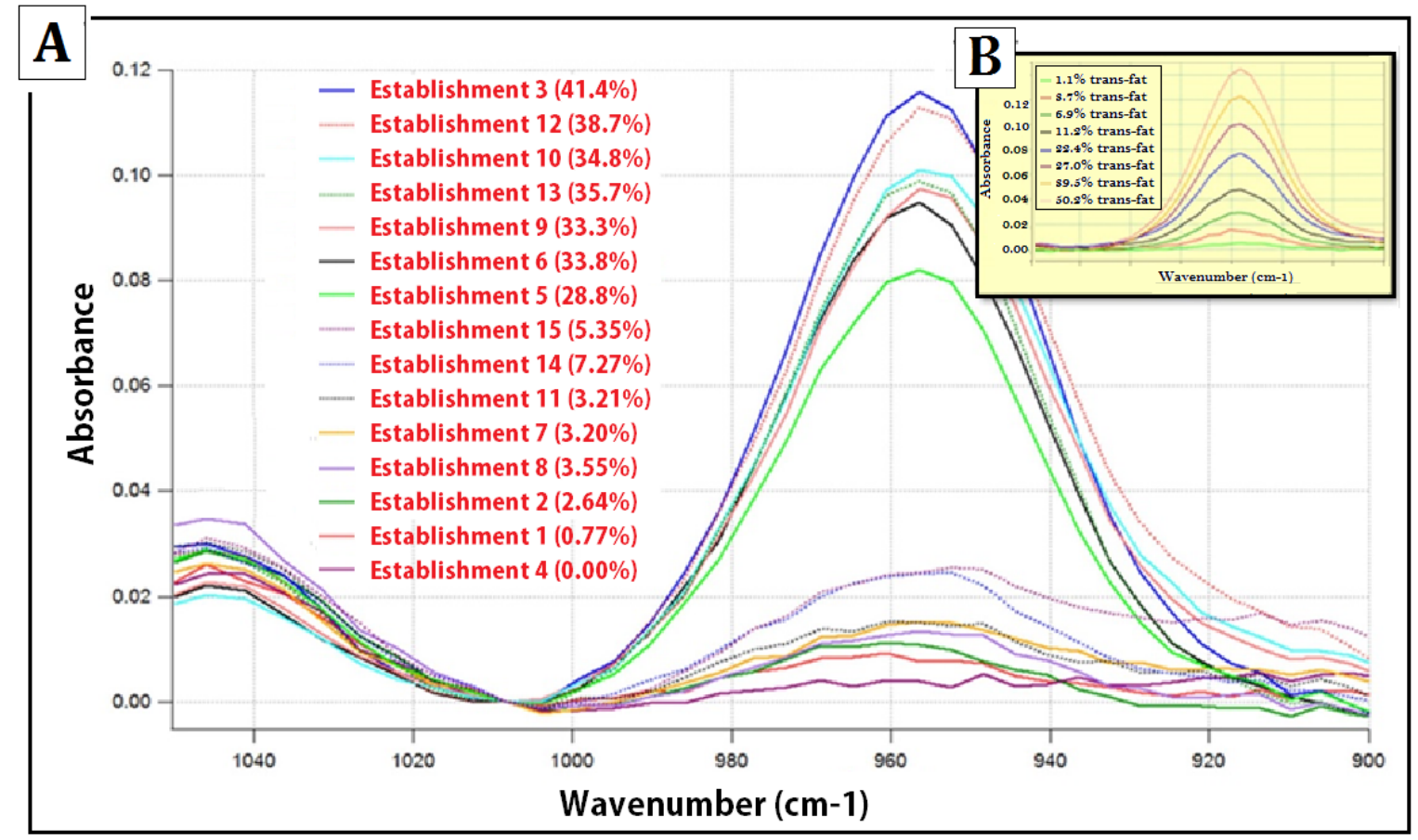

Fig. 3. VFA-IR Absorption Spectra of donut oil extractions (A) and Standards (B). The calibration of curve of the percent trans-fat versus peak area $\left(945-990 \mathrm{~cm}^{-1}\right)$ of the standards (not shown) yielded a linear equation of $\mathrm{y}=4.77 \times 10^{-5} \mathrm{x}+1.23 \times 10^{-4}, \mathrm{R}^{2}=0.9904$.

\section{References}

1. Graf P.A., Lemke S., Dirienzo M. (2008) Reducing the Trans-Fatty Acid Content in Foods. Nutr. Today, 43(2), 46-51.

2. Hu, F. B., Stampfer, M. J., Manson, J. E., Rimm, E., Colditz, G. A., Rosner, B. A., ... \& Willett, W. C. (1997). Dietary fat intake and the risk of coronary heart disease in women. N. Engl. J. Med., 337(21), 1491-1499. 
3. Willett W.C. (2006). Trans fatty acids and cardiovascular disease-epidemiological data. Atheroscler. Suppl., 7(2), 5-8.

4. Leth, T, Jensen, H G, Mikkelsen, A Æ, Bysted, A (2006). The effect of the regulation on trans fatty acid content in Danish food. Atheroscler. Suppl., 7(2), 53-56.

5. Revealing Trans Fats. (2003). FDA Consumer magazine. Pub No FDA05-1329C.

6. Willet WC, Mozaffarian D (2007). Trans fats in cardiac diabetes risk: An overview. Curr Cardiovasc Risk Rep, 1(1), 16-23.

7. Mozaffarian D, Willett W (2008). Trans fatty acids and cardiovascular risk: A unique cardiometabolic imprint? Current Medicine Group LLC. 2008, 9(6), 486-493

8. Trans fat. American Heart Association, Jan. 2009 http://www.americanheart.org/presenter.jhtml?identifier $=3045792$

9. FDA. (2013) Tentative Determination Regarding Partially Hydrogenated Oils; Request for Comments and for Scientific Data and Information. Federal Register: The Daily Journal of the United States Government, https://www.federalregister.gov/articles/2013/11/08/201326854/tentative-determination-regarding-partially-hydrogenated-oils-request-for-comments-and$\underline{\text { for }}$

10. National Conference of State Legislatures (2013) Trans Fat and Menu Labeling Legislation, http://www.ncsl.org/research/health/trans-fat-and-menu-labeling-legislation.aspx

11. The Philadelphia City Council (2007) Health Code. The Philadelphia Code, Section 6-307, http://legislation.phila.gov/attachments/3332.pdf

12. The Boston Public Health Commission's Board of Health (2008) Boston Public Health Commission's Trans Fat Regulation, http://www.bphc.org/whatwedo/healthy-eating-activeliving/boston-trans-fat-ban/Pages/Boston-Trans-Fat-Ban.aspx

13. New York City Department of Health and Mental Hygiene (2006) New York City Health Code Section 81.08, http://www.nyc.gov/html/doh/downloads/pdf/public/notice-adoption-hc-art8108.pdf

14. Jenkins S, Campbell P, Burch C. (2012) Are fast food "trans-fat" claims true? An Infraspec VFA-IR spectrometer analysis of trans-fat content in fast food French fried potatoes. Proceedings of the Indiana Academy of Science, 121(1), 8-16.

15. Bligh, E G and Dyer, WJ. (1959) A rapid method of total lipid extraction and purification. Can. $J$. Biochem. Physiol, 37, 911-917.

16. Sheppard A. J., Hubbard W. D. (1974) Prosser AR: Evaluation of eight extraction methods and their effects upon total fat and gas liquid chromatographic fatty acid composition analyses of food products. JAOCS, 51(9), 416-418

17. Wilks - A Spectro Inc. Company (2014) Trans Fatty Acid Measurement, http://www.wilksir.com/pdf/Trans\%20Fat_2-14.pdf A.O.C.S.,

18. Mossoba M., Milosevic V., Milosevic M., et al. (2007) Determination of total trans fats and oils by infrared spectroscopy for regulatory compliance. Anal. Bioanal. Chem., 389(1), 87-92

19. Mossoba, M M, Yurawecz, M P, \& McDonald, R E (1996) Rapid determination of the totaltrans content of neat hydrogenated oils by attenuated total reflection spectroscopy. J. Am. Oil Chem. Soc., 73(8), 1003-1009.

20. Tyburczy C., Magdi M., Rader J. (2013) Determination of trans fat in edible oils: current official methods and overview of recent developments. Anal. Bioanal. Chem., 405(17), 57595772 